\title{
The Application of Actor Network Theory in Medical Translation
}

\author{
Yunxia Cai, Peiying Guo \\ Shaanxi University of Science and Technology, Xi'an, China \\ Email:2734460445@qq.com
}

How to cite this paper: Cai, Y. X., \& Guo, P. Y. (2020). The Application of Actor Network Theory in Medical Translation. Open Journal of Modern Linguistics, 10, 599-605.

https://doi.org/10.4236/ojml.2020.105036

Received: September 6, 2020

Accepted: October 25, 2020

Published: October 28, 2020

Copyright $\odot 2020$ by author(s) and Scientific Research Publishing Inc. This work is licensed under the Creative Commons Attribution International License (CC BY 4.0).

http://creativecommons.org/licenses/by/4.0/

(c) (i) Open Access

\begin{abstract}
Based on the Latour's actor network theory, this paper expounds the successful application of the theory in medical translation by paying attention to non-human actors, problematic cooperation mechanism and real signs of translation completion, so as to try to put forward theoretical principles that can guide medical translation.
\end{abstract}

\section{Keywords}

Latour's Actor Network, Medical Translation, Translation Theory Principles

\section{Introduction}

At present, under the background of global network, with the increasingly close exchanges and cooperation between China and the West, Chinese and Western medicine has been developing continuously. Therefore, translation as a tool for the development has become particularly essential.

In the translation of scientific English, the translation of medical English is an important part. Only through the translation of medical English can foreign advanced medical texts be effectively and accurately introduced, so as to promote the continuous progress and development of domestic medicine.

China has made great achievements in the study of medical English translation, especially in the study of TCM Translation. Tracing back the history of medical English translation studies in China in recent years, it can be seen that medical English translation studies are mainly application-oriented and focus on various translation techniques and error analysis. The study of medical English translation theories is a mere drop in the ocean, far from forming a system.

Therefore, for the study of medical English, the author believes that applicable translation theory principles should be established to support and guide the 
practice of medical English translation. With practical examples, this paper aims to illustrate the guiding role of Latour's actor network theory in the context of machine-assisted medical translation.

\section{Actor Network Theory}

In the 1980s, French sociologists Bruno Latour and Michel Callon proposed the renowned actor-network theory (ANT for short) which was developed by John Law. As one of the important theories of sociology, in early studies, ANT is used to explore social phenomenon, while it has been commonly used in interdisciplinary research lately.

Helene Buzelin, a Canadian scholar, was the first to introduce the theory of actor network into translation studies. In the Unexpected Allies. How Latour's Network Theory could Bourdieusian Analysis in Translation Studies (2005). Buzelin points out that translation and network play an important role in translation studies by using actor theory (Buzelin, 2005: p. 196).

There are three core concepts in the theory of actor network: actor, network and translation. These three core concepts have their own characteristics and are related to each other. The actor and the network are mutually constructed. The network forms, extends and transforms in the interactive connection of the actor. The actor exists in the network and obtains the definition of identity in the network. Translation acts as a "catalyst" that drives the process.

People's interest relationship and purport are different in the society. "Translation" is to transform the interests of one actor into those of other actors or vice versa. "Translation is defining roles, assigning roles, describing assumptions. It speaks for other actors in its own language.... Translation, however, should not be taken lightly, for it only really comes into being when all parties are producing for the same goal" (Callon, 1986a: p. 26). Only on the basis of the "translation" of mutual interests, can a strong and stable network be built. "Shifting interests also means providing new interpretations of these interests and drawing people in different directions" (Callon, 1987: p. 117). In addition, "translation" means not only the transformation of interests, but also the definition of actors.

Translation is a continuously changing process, and that is the reason why Callon (1986b) has actually divided it into four stages: 1) problematization, in which the focal actor establishes itself as an obligatory passage point between the larger network and the actors that it seeks to represent; 2) interessement, in which actors' interests are aroused and in which the terms of their involvement in the actor-network are negotiated. At this point, the focal actor also strives to "translate" the network, or, to put it differently, to convince the other actors that the roles it has defined for them are acceptable; 3) enrolment, in which the actors accept the roles that have been defined for them; and, finally, 4) mobilization of allies, in which the focal actor maintains its crucial position as well as the commitment of the actors it claims to represent. "Translation" in the ANT sense is further enforced by circulating inscriptions into the actor-network, thus ensuring that the focal actor's interests are protected. 
These four keys can be said to be the model of the translation process in the context of machine assisted translation. In modern society, language service is no longer a simple individual translation, but a cooperative mode. In this context, Latour's actor network theory is bound to become the first theoretical guiding principle in translation.

In recent 10 years, "sociological turn" comes into the western translation. Translation is one of the latest progress of production process research, which focuses on analysis of various actors (also known as actors) how to together build and operate a network, thus the target of literary translation within the field of production, dissemination and accepted, providing an effective tool for our study of overseas Chinese literature spread theory. In recent years, Huang Dexian (2006), Xing Jie (2015, 2016, 2019), Li Hongman (2008), Sun Ningning (2010), Yang Xiaohua (2011), Wang Chuanying (2013), Xu Minhui (2013), Zhong Weihe and Feng Man (2014), Wang Hongtao (2016), Wang Xiulu (2019) interpret the sociology of western translation theories and research achievements, and began to publish applied research, but so far used mainly by Pierre Bourdieu (Pierre Bourdieu) theory, the analysis of the translation of the production process is still rare.

This paper using Bruno Latour (Bruno Latour) actor network theory, by attaching great importance to the cooperation mechanism of non-human actors, problems, and translation to complete the real sign of three aspects, explains the Latour actor network theory in the successful application of medical translation, which can guide the medical translation theory principles are put forward.

\section{The Application of Actor Network Theory in Medical Translation}

Firstly, the original medical text should be also considered as an actor. Compared with other sociological theories, the most distinctive feature of the theory of actor network lies in the definition of "actor". The theory holds that actors are heterogeneous, dynamic and uncertain. In addition to "human" with active behaviors, it also includes many "non-human" such as objects, instruments, programs, concepts, technologies and organisms. Therefore, the concept of "actor" includes not only the conventional "agent", but also the material force that makes other actors act. Latour always called "actor" (an actor is what is made to act by many others) (Buzelin, 2005: p. 46). In the translation process of medical texts, from the perspective of the concept of actors, human actors involved do not regard the original texts as sacred and inviolable texts, but as important "actors" or "actors" who initiate new social networks. They are not influenced by traditional translations believing that the original texts are static and cannot be modified.

The following examples are given to demonstrate the full play of the dynamic role of medical text.

The source text: 快速血糖水平提供了一个人的身体如何管理血糖的重要线 索。血糖通常在进食后约一小时达到峰值, 然后下降。 
The target text: Fasting blood sugar levels give vital clues about how a person $s$ body is managing blood sugar. Blood sugar tends to peak about an hour after eating and declines after that.

Analysis: It is very confused that the author has been aware of fasting blood sugar meaning 空腹血糖 before the medical translation training, but the original text has been translated as the 快速血糖. By referring to network, history reference and customer reference, verification by talking with others, determining the possibility of wrong original text, the original cannot be seen as the fixed text, but by taking the actor's subjective initiative, validation, correct feedback, eventually with proper translation for the final version. So the translators are not under the bondage of traditional translation concepts in the process of the whole sentence translation, but proceed from success to establish the goal of translation network and bold to compile the original text, also conforming to the actor network on translation ethics recognized by ethics: "from the so-called (the world of matters of fact) to (the worlds of matters of concern)" (Wolf, 2005: p. 116).

Secondly, it is the cooperative mechanism of the problematic process in medical text translation. Actors network translation based on the sociology perspective, which focused on those established facts not foreseen in the history of science and sociology of science. It is actors' action through cooperation, to set up the social network, and this process is dependent on the initial agent (agency) for each "action" interests "translation". The most critical step in this "translation" is the "problematic process", which is "a way of controlling the behaviour of others and making oneself indispensable by pointing out their problems and proposing specific solutions" (Callon, 1986a: p. XVII).

From the perspective of the problematic process, the success of medical translation activities is to meet the current situation of the developed machine translation in the world. People can use the machine translation network communication tools and cooperate with all relevant personnel to process medical translation problems, so as to achieve high-quality translation. The cooperative mechanisms for translating a specific word are as follows: for example, translating the name of a hospital.

The source text: 解放军 301 医院

The target text 1: Chinese PLA General Hospital

The target text 2: Medical School of Chinese PLA

The target text 3: General Hospital of the People's Liberation Army

The target text 4: General Hospital of the People's Liberation Army (PLAGH)

Analysis: When translating the 301 Hospital of PLA, if the client requires a standard translation, it will be translated according to the client's requirements. If there is no requirement, it will be translated based on the specific text. If the translator, 1J, 2J disagree, then the online meeting should be hold to discuss. If you can't decide yet, trying to discuss through the network resources to determine, such as official translation version, website, senior translators, consult experts. If cannot solve, note to the customer with the last final version. This is a network mechanism running in a specific translation field, in which actors coo- 
perate with each other, link by link, and use various machine aids to solve problems collectively in a specific translation links, rather than the earlier one-person translation mode.

The last important aspect is that the finished mark of medical text translation-interessement giving, recruitment and mobilization. Translator completed it does not mean the translation itself finally ended. It is just "problematic process" from the perspective of actor network theory and the demand side or reader hasn't really set up between the network, the complete "translator/translation" should also be include "decided interest, recruitment and mobilization", becoming "obligatory points of passage" which is the symbol of the success of the network of actors (Callon, 1986b: p. 6).

Medical translation companies just have a set of relatively good translation procedures. They are not satisfied with the translation of only the translator, but continue to act and actively mobilize $1 \mathrm{~J}$ and $2 \mathrm{~J}$ to review with reasonable arrangement of quality inspection, constantly strive for perfection in order to get high-quality translation.

According to the theory of actor network, no matter how strong an actor is, it is impossible for him to complete an action by himself. Other actors in the network also can gain energy and work together to effectively accomplish the action. As medical translation texts are extremely cautious, recruiting translation companies, especially those with strong positions, is the trickiest issue for Western medicine trying to enter the Chinese market. So, how to recruit well-known translation companies? Long-term cooperation, brand effect, social propaganda and so on. As the company, hundreds of famous medical company, some customers are long-term cooperation, which almost translate the same texts for a week from different departments. It shows the translation of medical demand has a fixed amount. So the company should give stakeholders important role and put it into the translation if you want to cooperate for a long time.

All actors in the network in the theory of actor network have equal status, but one actor has to recruit other actors.

In order to form a network of interactive relationships, the actor is the demand side of the interest-the customer. The other actors are all the staff involved in the project within the translation company, including the project manager, team leader, part-time translator, pre-translation, 1J, 2J, editor, CN/EN maker, customer service staff, submission staffs, etc. The construction and execution of translation network are required before, during and after translation.

In order to illustrate the whole process of medical text translation under the guidance of actor network, the author tries to use the following diagram:

Customer order $\rightarrow$ project analysis $\rightarrow$ select the corresponding project plan $\rightarrow$ pre-translation editing $\rightarrow$ Translation $\rightarrow$ proofreading ( 2 times) $\rightarrow$ typesetting after translation $\rightarrow$ editing $\rightarrow$ final draft $\rightarrow$ timely submission $\rightarrow$ customer feedback $\rightarrow$ update terms $\rightarrow$ finished the tasks

As shown in the figure above, it is clear that the completion of translation is not the real end, but also needs to lock the interests of customers and mobilize 
other actors, such as the editors, typesetters and translation, to work together to complete the translation task.

\section{Conclusion}

It can naturally be arrived at the conclusion from the above analysis, that due to the unique language characteristics of medical texts and the lack of medical translators, the translation habits of medical texts are blooming and uneven which reflected in the selection of translation materials (rigorous objective standards), translation concept (reader first, serving the market), translation strategy (faithfulness and creativity), translation method (academic and commercial). This habit helps translators to win in the market battles and gradually accumulate capital to successfully translate many medical texts and related works.

The production of medical translation relies on the effective cooperation of a network of actors, including a translation initiation network, a translation delivery network and a translation production network. The habituation of the translator determines that the translation method of medical texts is both academic and commercial. It has both the faithful and rigorous and the flexible. The reader-first and market-serving translation principle makes medical text translation tend to be moderately easy to compile the original text. The editor's intervention in the original text and the translator has exacerbated this tendency to delete and modify; on the other hand, it pays attention to the means of reproducing the original work, retaining the meaning of medical culture by several translators.

With Latour's actor network theory, the lack of abilities of translators is greatly solved by group cooperation and machine assistance. And then the two parties' interests are limited, making the translation production process more rigorous, accurate, efficient, reasonable, and standard. To achieve the role of communication, the facts have proved that this theory can indeed provide effective guidance for the medical translation.

\section{Conflicts of Interest}

The authors declare no conflicts of interest regarding the publication of this paper.

\section{References}

Buzeli, H. (2005). Unexpected Allies: How Latour's Network Theory Could Complement Bourdieusian Analyses in Translation Studies. The Translator, 11, 193-218. https://doi.org/10.1080/13556509.2005.10799198

Callon, M. (1986a). The Sociology of an Actor-Network: The Case of the Electric Vehicle. In M. Callon, J. Law, \& A. Rip (Eds.), Mapping the Dynamics of Science and Technology: Sociology of Science in the Real World (pp. 19-34). London: Macmillan Press. https://doi.org/10.1007/978-1-349-07408-2_2

Callon, M. (1986b). Some Elements of a Sociology of Translation: Domestication of the Scallops and the Fishermen of Saint Brieuc Bay. In J. Law (Ed.), Power, Action and Be- 
lief: A New Sociology of Knowledge. Boston, MA: Routledge.

Callon, M. (1987). Society in the Making: The Study of Technology as a Tool for Sociological Analysis. In W. E. Bijker, T. P. Hughes, \& T. J. Pinch (Eds.), The Social Construction of Technological Systems. Cambridge, MA: MIT Press.

Huang, D. X. (2006). Translation: Existing in the Network. Shanghai Translator, No. 4, 6-11.

Li, H. M. (2008). Pierre Bourdieu and the Theoretical Construction of the Sociology of Translation. Chinese Translators, 29, 30-33.

Sun, N. N. (2010). Actor Network Theory and Training of Market-Oriented Talents of Translation and Interpretation. Research and Practice of Higher Education, 29, 47-49.

Wang, C. Y. (2013). Sociological Reinterpretation of Translation Norm Theory. Shanghai Translators, No. 3, 14-19.

Wang, H. T. (2016). Socio-Translation Studies: The Name and Nature of a Discipline under Construction. Chinese Translators, 37, 6-13+127.

Wang, X. L. (2019). Research on Actor Network Translation. Shanghai Translator, No. 2, 14-20.

Wolf, M. (2005). Power to the Agents in Translation: Towards a Sociology of Translation. Translating and Interpreting as a Social Practice International Conference Abstract.

Xing, J. (2015). Translators' “Habitus": A New Perspective on Descriptive Translation Studies. Chinese Translators, No. 3, 27-31+72.

Xing, J., Chen, H. C., \& Cheng, X. (2016). The Sociology of Translation Studies Turns Twenty: Past, Present and Future. Chinese Translators, 37, 14-20+127.

Xing, J., Li, Y. P., \& Zhang, Q. F. (2019). Latour's Actor-Network Theory and Its Conceptual Potentials for Translation Studies. Chinese Translators, 40, 28-36+188.

Xu, M. H. (2013). From the Change of the End of the English Translation of "Bozi": A Sociological Perspective of Translation. Chinese Translators, 34, 74-78.

Yang, X. H. (2011). The Theoretical Framework and Research of Translation Sociology: Taking China's Language Service Industry as an Example. Shanghai Translator, No. 3, 7-12.

Zhong, W. H., \& Feng, M. (2014). The Construction of a Cultural Translation Research System from the Perspective of Translation Sociology. Foreign Language Studies, No. 3, 57-62. 